\title{
Study on the factors that influence the intention of college students to participate in the green building
}

\author{
ChienJen Hung ${ }^{1, a}$, Chenchen Lai ${ }^{1}$ and Meiyan Chen ${ }^{1,2}$ \\ ${ }^{1}$ Department of Civil Engineering, Fuzhou College of Foreign Studies and Trade, Fuzhou \\ ${ }^{2}$ PhD program, Department of Business Administration, National Chengchi University, Taipei City 11605, Taiwan
}

\begin{abstract}
The concept of green building has been extended for a period of time on both sides of the Taiwan Strait. However, there still is curiosity and skepticism in Fujian on green building. While in Taiwan, villages are filled with green-evolved houses and modern environmental farmhouses. With Theory of Planned Behavior as the framework, this study investigates influences of college students' attitude toward green building, subjective norms of green building and perceived behavioral control of green building on the intention to participate in the green building. Findings show that college students' attitude toward green building and the perceived behavioral control of green building significantly influence the intention to participate in the green building, but "subjective norms of green building" doesn't have significant influence. The reason is probably that college students are at the rebellious stage and have high self consciousness and independent viewpoints.
\end{abstract}

\section{Introduction}

Green building means that, on the basis of green culture, try best to choose materials of the nature and design energy-saving and comfortable living space in the process of construction behavior in order to achieve environmental protection and retard environmental deterioration. Therefore, a building should meet not only basic functional requirements but also fundamental requirements of green architecture, i.e. focusing on human physical and mental needs as well as providing people living in the building with convenience, comfort and physical and mental health. In this paper the intention of college students to participate in the green building mainly refers to their intention to promote and change houses into green buildings. The concept of green building has been popularized for many years on both sides of the Taiwan Straits. In Taiwan, many representative green buildings have been erected. In Fujian province of Mainland China, green building has been supported by the government and its promotion is still in progress. With regard to the government's policy and support of environmental protection, the State Council issued Comments on Accelerating the Development of Energy-Saving and Environment-Friendly Industries in August 2013, which clearly defines four key missions for enhancing development of energy-saving and environment-friendly industries.This is extremely significant for Chinese government's responsibilities in the environment. Evaluation standard for green building (GB/T50378-2006) ${ }^{[1]}$, published and implemented in 2006, clearly describes definition, evaluation indicators and evaluations methods of green building. Since enforcement, this standard has

\footnotetext{
${ }^{a}$ Corresponding author : kukusau8@ foxmail.com
} 
been used to effectively guide practical works of green building in China. In Implementation Scheme for Green Building Action of Fujian Province, it is clearly indicated that the major goal of this plan is to make $40 \%$ of newly-constructed urban and town buildings meet requirements of green building standard in 2020. "Accelerating green building technology innovation", "striving to develop emerging industries like green construction materials", "launching publicity and education" and other similar works are also mentioned.

Thanks to promotion by government and media in these years, common people have become familiar with green building. However, before cost is reduced to an acceptable level, there is a big gap from people's actual buying green building or their intention to renovate original house into green building. After completing studying, college students will become the core force of the society. Their behaviors exert great influence on the society. With students from a private university in Fujian province as the objects, this study is aimed to (1) investigate college students' intention to participate in green building; (2) investigate influences of different factors such as college students' attitude toward green building and subjective norms of green building on the intention to participate in the green building; (3) discuss and formulate management implications.

\section{Literature review}

Definitions of green building are available in many papers. For example, as described by W. Zhang \& B. Li. (1998) ${ }^{[2]}$, green building system is a new architecture system established based on principle of virtuous circle of ecosystem, with green economy as the foundation, green society as the connotation, green technology as the support and green environment as the mark. According to Evaluation standard for green building (2006) ${ }^{[1]}$, within its total life cycle, green building should maximally save resources (energy, land, water and materials conservation), protect environment, reduce pollution, provide people healthy, practical and high-efficiency use space, and achieve harmony with the nature. "Green building" is a term encompassing strategies, techniques, and construction products that are less resource-intensive or pollution-producing than "regular" construction. (A. J. Hoffman \& R. Henn, 2008). ${ }^{[3]}$

Many researches on green building have been published in recent years. Through investigating rainwater collecting facilities of green buildings in housing estate of Changsha City, W. Zhang, Y. Huang, W. Xiao, L. Yang \& Z. Xiong (2015) ${ }^{[4]}$ suggested that roofing rainwater collecting system features relative small investment and easy management and maintenance, and thus can be a part of energy-saving building. X. Chen \& Y. Li $(2015)^{[5]}$ studied application of green building theory into design of ruins museum. They pointed out, to enhance our abilities of ecological architecture design, it's necessary to use the experience of other countries for reference, stick to human-centered principle of design, and construct ecological-type ruins museum adapt to China. X. Qin \& L. Jing (2013) ${ }^{[6]}$ conducted descriptive statistical analysis and inferential statistical analysis using SPSS, in order to investigate evaluation of risk factors of green building during the entire life cycle. The present study chooses college students as the objects, and discusses factors that influence the intention to participate in green building.

In theory of reasoned action, behavioral intention is an antecedent factor of behavior and influenced by Attitude and Subjective Norm. Theory of planned behavior adds Perceived Behavioral Control into theory of reasoned action and includes act of the will in the discussed model, and thus can better predict behavior (J. Zhang \& Q. Zheng, 2012) ${ }^{[7]}$. Researches with regard to application of theory of planned behavior include study by Lao Kefu and Wu Jia (2013) ${ }^{[8]}$, which used theory of planned behavior to discuss influencing mechanism of green consumer behavior. They found subjective norm and perceived behavioral control of green consumption significantly influenced consumer's intention to participate in green consumption and such intention also has significant influence on green consumption behavior; however, attitude toward green consumption doesn't exert direct and significant influence on the intention to participate in green consumption. H. Zhang, C. Bai \& C. Li. $(2011)^{[9]}$ utilized theory of reasoned action and theory of planned behavior to investigate consumers' intention to go shopping online; findings showed attitude and perceived behavioral control 
significantly influenced online shopping intention but influence of subject norm was not significant. L. Lin \& X. Bai. (2014) ${ }^{[10]}$ used theory of planned behavior to investigate university students' delay behavior. They pointed out, more active attitude toward specified task results in stronger perceived behavior control, stricter subjective norm of accomplishing tasks on schedule, stronger behavioral intention and reduced delay behaviors. Theory of planned behavior is a good integrated theoretical framework for delay behavior researches. F. Boudreau\&G. Godin (2009) ${ }^{[11]}$ used theory of planned behavior to investigate patient's physical activity intention.

\section{Research hypotheses}

Based on theory of reasoned action, the present study attempts to investigate influences of college students' green building attitude (GBA), green building subjective norm (GBSN) and green building perceived behavioral control (GBPC) on green building behavioral intention (GBBI). Following hypotheses are proposed on the basis of literature data construction.

Hypothesis 1 (H1): there is positive interrelationship between college students' GBA and GBSN. According to theory of planned behavior put forward by Ajzen (1991) ${ }^{[12]}$, positive interaction effects exist between human's attitude toward certain behaviors and their subjective norm. For college students, green building is a rational behavior constricted by subjective conditions. Their GBA and GBSN influence each other. Once more active in green building, college students will be more likely to feel a greater influence by social norms. Meanwhile, in case of more active attitude toward environmental protection, college students will perceive stronger influence from the society or relatives and friends. Consequently, interrelationship between GBA and GBSN is positive.

Hypothesis 2 (H2): there is positive interrelationship between college students' GBSN and GBPC. According to theory of planned behavior put forward by Ajzen (1991) ${ }^{[12]}$, positive interaction effects exist between human's subjective norm of certain behaviors and their perceive behavioral control. With stronger GBSN, college students will make more preparations for green building and form stronger GBPC. Also, in case of more sufficient conditions for green building, college students will more strongly hope that more people can recognize and participate in green building in order to generate a better ecological environment. Therefore, GBSN and GBPC affect each other and such mutual influence is positive.

Hypothesis 3 (H3): there is positive interrelationship between college students' GBA and GBPC. According to theory of planned behavior put forward by Ajzen (1991) ${ }^{[12]}$, positive interaction effects exist between human's attitude toward certain behaviors and their perceive behavioral control. College students who hold active attitude toward green building behavior are willing to make more preparations and have stronger perceived behavioral control. College students who have stronger GBPC will form stronger expectation of good ecological environment and become more active in green building. Consequently, interrelationship between GBA and GBPC is positive.

Hypothesis 4 (H4): college students' GBA positively influences GBBI.

It is describe in Ajzen's (1991) ${ }^{[12]}$ theory of planned behavior that people's attitude toward certain behaviors will influence their behavioral intention. Occurrence of GBBI firstly depends on GBA. More active attitude is associated with consumer's stronger desire for green building. Therefore, college students' GBA has positive influence on their green building intention.

Hypothesis 5 (H5): college students' GBSN positively influences GBBI.

As mentioned in Ajzen's (1991) ${ }^{[12]}$ theory of planned behavior, people's subjective norm of certain behaviors will influence their behavioral intention. Mostly, green building behavior is a kind of reasoned action. Consumers who perceive greater pressure from surrounding people will generate a stronger intention of green building. College students' GBSN also exerts positive influence on their intention to participate in green building.

Hypothesis 6 (H6): college students' GBPC positively influences GBBI.

According to Ajzen's (1991) ${ }^{[12]}$ theory of planned behavior, people's perceived behavioral control of certain behaviors will positively influence their behavioral intention. This is an important expression of influence of personal behavior on objective condition constrictions. Green building behavior is a 
kind of action constricted by certain objective conditions. If consumers feel they have more active capabilities and conditions for conducting green building behavior, they will form a stronger intention to participate in green building. Therefore, GBPC positively influences GBBI.

\section{Questionnaire design and survey result}

Table 1. Setting of questionnaire items (variables).

\begin{tabular}{|c|c|c|}
\hline \multirow{4}{*}{ GBA } & Q11 & I agree that green building can reduce urban heat island effect. \\
\hline & Q12 & $\begin{array}{l}\text { I agree that green building can insulate heat, lower down temperature and make the } \\
\text { space inside house refreshing and comfortable. }\end{array}$ \\
\hline & Q13 & I agree that green building can beautify environment. \\
\hline & Q14 & $\begin{array}{l}\text { I agree that green building can protect environment, reduce pollution and provide } \\
\text { people healthy and nature-friendly building. }\end{array}$ \\
\hline \multirow{5}{*}{ GBSN } & Q21 & $\begin{array}{l}\text { I think teacher's behaviors and attitudes about green building influence my behavior } \\
\text { and attitude. }\end{array}$ \\
\hline & Q22 & $\begin{array}{l}\text { I think parents or relatives' behaviors and attitudes about green building influence my } \\
\text { behavior and attitude. }\end{array}$ \\
\hline & Q23 & $\begin{array}{l}\text { I think friends' behaviors and attitudes about green building influence my behavior and } \\
\text { attitude. }\end{array}$ \\
\hline & Q24 & $\begin{array}{l}\text { I think the government's behaviors and attitudes about green building influence my } \\
\text { behavior and attitude. }\end{array}$ \\
\hline & Q25 & $\begin{array}{l}\text { I think TV media's behaviors and attitudes about green building influence my behavior } \\
\text { and attitude. }\end{array}$ \\
\hline \multirow{4}{*}{ GBPC } & Q31 & $\begin{array}{l}\text { 1. When I can't find trash can outside, I will temporarily wait and throw the rubbish } \\
\text { when trash can is available. }\end{array}$ \\
\hline & Q32 & $\begin{array}{l}\text { 2. When friend conducts behavior of wasting earth resources, I will persuade him/her } \\
\text { not to do so. }\end{array}$ \\
\hline & Q33 & 3. I persist in $\mathrm{CO} 2$ emission reduction and energy saving whenever and wherever. \\
\hline & Q34 & 4. I often use mass transportation for saving natural resources. \\
\hline \multirow{5}{*}{ GBBI } & Q01 & $\begin{array}{l}\text { I want to change my house into a green building that can insulate heat, lower down } \\
\text { temperature and provide a refreshing and comfortable home. }\end{array}$ \\
\hline & Q02 & I want to change my house into a green building for beautifying environment. \\
\hline & Q03 & $\begin{array}{l}\text { I want to participate in promotion of green building for protecting environment of the } \\
\text { earth. }\end{array}$ \\
\hline & Q04 & $\begin{array}{l}\text { I'm willing to change my house into a green building for becoming a pioneer in } \\
\text { environmental protection. }\end{array}$ \\
\hline & Q05 & I want to own a green building. \\
\hline
\end{tabular}

This questionnaire is mainly for inquiring college students' green building behaviors such as attitude, subjective norm, perceived behavioral control and intention. Questions are set according to Ajzen's (1991) [13] theory of planned behavior and related literatures (L. Lin \& X. Bai. , 2014 ; H. Zhang, C. Bai \& C. Li. , 2011) ${ }^{[9,10]}$ (see table 1). There are four questions (variables) about college students 'GBA- Q11, Q12, Q13 and Q14, five questions (variables) about GBSN-Q21, Q22, Q23, Q24 and Q25, four questions (variables) about GBPC-Q31, Q32、Q33 and Q34, and five questions (variables) about GBBI- Q01, Q02, Q03, Q04 and Q05. In addition, interviewees' basic data are asked, including gender, age, family income, major, department and parents occupation. Five-point Likert scale is used. Option and corresponding score of each question (variable) is as the following: quite agree ( 5 points), agree ( 4 points), no opinion ( 3 points), disagree ( 2 points) and quite disagree (1 point).

Survey of this study was done at a private university of Fujian Province from April 8 to April 15, 2016. Six teachers sent 497 questionnaires to 11 departments. 443 valid questionnaires were recycled, accounting for $89.13 \%$. Survey was performed by means of randomly choosing students and asking them to complete questionnaire on site. 
In valid questionnaires, male and female students made up $33.7 \%$ and $66.1 \%$ respectively. In terms of age, students born in 1997, 1996, 1995, 1994, 1993 and other years accounted for 10.4\%, 15.8\%, 30\%, $34.1 \%, 8.4 \%$ and $1.1 \%$ respectively. With regard to father's occupation, industry, commerce, agriculture, public office, teacher, freelance work, unemployment, others and no statement accounted for $14 \%, 27.4 \%, 27.8 \%, 6.2 \%, 1.8 \%, 15.9 \%, 2.1 \%, 4.7 \%$ and $1.8 \%$ respectively. With respect to place of household registration, Fujian, other province and no statement accounted for $91.2 \%, 5.6 \%$ and $3.2 \%$ respectively. In terms of family income, "below 4000", "4000-6000", "6000-10000", "1000015000", "above 15000" and "no statement" accounted for 21.4\%, 24.4\%, 20.5\%, 12.4\%, $11.7 \%$ and 9.5\% respectively. Regarding department, English, Asia-Europe language, economy \& trade, logistics, information, business \& administration, financing \& accounting, engineering, television \& film, arts $\&$ design, and statement accounted for $9.5 \%, 9.9 \%, 8.4 \%, 10.6 \%, 8.8 \%, 9.0 \%, 8.8 \%, 5.6 \%, 9.3 \%$, $9.3 \%, 9.5 \%$ and $1.4 \%$ respectively.

In analysis of the interviewee data variable "intention to participate in green building" there was significant different between different genders $(\mathrm{P}=0.021, *)$ and female is superior to male student. Interviewees showed obvious differences in monthly family income $(\mathrm{P}=0.003, * *)$. Analysis by scheffe method demonstrated, students from family with monthly income below 4000 (RMB) were superior to those from family with monthly income of 10000-15000 (RMB) in terms of the intention to participate in green building. There were also significant differences between interviewees studying in different departments $(\mathrm{P}=0.012, *)$. Engineering department presented the highest score, followed by arts \& design department. Aisa-Europe Language Department had the lowest score. However, analysis by scheffe method showed no significant difference. Interviewees' age and their parents' occupation didn't lead to significant difference.

\section{Modeling fitting and hypothesis testing}

\subsection{Date reliability and validity testing}

Table 2. Test indicators and fitting results of measurement model.

\begin{tabular}{|c|c|c|c|c|c|c|}
\hline Latent & Observation & Cronbach & Estimate & Std. & CR & $\mathbf{P}$ \\
\hline \multirow{4}{*}{ GBA } & Q11 & \multirow{4}{*}{0.855} & 1.000 & & & \\
\hline & Q12 & & 1.086 & .070 & 15.426 & **** \\
\hline & Q13 & & 1.077 & .073 & 14.772 & $* * *$ \\
\hline & Q14 & & 1.132 & .071 & 16.051 & $* * *$ \\
\hline \multirow{5}{*}{ GBSN } & Q21 & \multirow{5}{*}{0.899} & 1.000 & & & \\
\hline & Q22 & & 1.015 & .045 & 22.709 & $* * *$ \\
\hline & Q23 & & 1.012 & .044 & 23.066 & **** \\
\hline & Q24 & & .810 & .049 & 16.466 & $* * *$ \\
\hline & Q25 & & .760 & .046 & 16.407 & $* * *$ \\
\hline \multirow{4}{*}{ GBPC } & Q31 & \multirow{4}{*}{0.823} & 1.000 & & & \\
\hline & Q32 & & 1.101 & .061 & 18.063 & $* * *$ \\
\hline & Q33 & & .819 & .060 & 13.603 & $* * *$ \\
\hline & Q34 & & .970 & .070 & 13.849 & $* * *$ \\
\hline \multirow{5}{*}{ GBBI } & Q01 & \multirow{5}{*}{0.856} & 1.000 & & & \\
\hline & Q02 & & 1.244 & .089 & 14.013 & $* * *$ \\
\hline & Q03 & & 1.241 & .087 & 14.285 & $* * *$ \\
\hline & Q04 & & 1.379 & .095 & 14.469 & $* * *$ \\
\hline & Q05 & & 1.000 & .088 & 11.390 & $* * *$ \\
\hline
\end{tabular}

This study used SPSS20.0 to carry out reliability testing of all of the 18 observation variables. The obtained reliability testing indicator- Cronbach $\alpha$ value was 0.899. Cronbach $\alpha$ values of four 
variables- GBA (Q11, Q12, Q13 and Q14), GBSN (Q21, Q22, Q23, Q24 and Q25), GBPC (Q31, Q32, Q33 and Q34) and GBBI (Q01, Q02, Q03, Q04 and Q05) were 0.855, 0.899, 0.823 and 0.856 respectively (as listed in table 2), indicating good reliability of data. This study used AMOS 20.0 to analyze confirmatory factors. Analysis results showed that standardized estimates (Std. Estimate) of observation variables corresponding to GBA, GBSN, GBPC and GBBI all exceeding the benchmark value- 0.5 and all estimates were of significant level ( $\mathrm{P}<0.001, * * *)$ (as listed in table 2$)$, indicating latent variables of the present study had good convergent validity. Comparison of square root of Average Variance Extracted (AVE) of each latent variable and correlation coefficient of each latent variable calculated based on results of confirmatory factor analysis demonstrated, GBA, GBSN, GBPC and GBBI were highly correlated with each other. This conforms to viewpoint of theory of planned behavior (Ajzen, 1991). Furthermore, correlation coefficient of latent variable is not larger than square root of AVE (as listed in table 3). According to above testing results of convergent validity and discriminant validity, survey data of this study passes validity test.

Table 3. Discriminant validity testing of latent variables.

\begin{tabular}{|c|c|c|c|l|}
\hline & GBA & GBSN & GBPC & GBBI \\
\hline GBA & $\mathbf{0 . 7 7}$ & $\leftarrow$ & $\sqrt{\mathrm{AVE}}$ & \\
\hline GBSN & 0.33 & $\mathbf{0 . 8 0}$ & $\downarrow$ & \\
\hline GBPC & 0.43 & 0.42 & $\mathbf{0 . 7 5}$ & $\searrow$ \\
\hline GBBI & 0.51 & 0.43 & 0.75 & $\mathbf{0 . 7 5}$ \\
\hline
\end{tabular}

\subsection{Fitting results}

This study used AMOS20.0 to perform structural equation model fitting for the data of the obtained 443 questionnaires and the theoretical model of green building behavioral intention. Table 4 shows fitness test indicators of the fitting. Freedom degree of chi-square value of this study is 3.081 , near the ideal boundary value-3. RMSEA value is 0.069 . RMSEA value between 0.05 and 0.08 is good. Besides, other important fitness test indicators of this study, including NFI, GFI, CFI, RFI, IFI, TLI and AGFI, are all greater than or close to 0.9, suggesting very good fitness evaluation results. Theoretical model and survey data of this study can be subject to good fitting (as listed in table 4).

Table 4. Fitness test indicators

\begin{tabular}{|c|c|c|c|c|c|}
\hline $\begin{array}{c}\text { Power of } \\
\text { statistical test }\end{array}$ & Indicator & $\begin{array}{c}\text { Standard } \\
\text { value }\end{array}$ & $\begin{array}{l}\text { Green building } \\
\text { intention model }\end{array}$ & $\begin{array}{c}\text { Reach or } \\
\text { not }\end{array}$ & Remarks \\
\hline \multirow{6}{*}{$\begin{array}{l}\text { Absolute } \\
\text { fitness }\end{array}$} & $\mathrm{X}^{2}$ & & 397.451 & $\sqrt{ }$ & \\
\hline & $\mathrm{X}^{2} / \mathrm{df}$ & $1 \sim 5$ & 3.081 & $\sqrt{ }$ & \\
\hline & GFI & $>0.9$ & 0.910 & $\sqrt{ }$ & \\
\hline & AGFI & $>0.9$ & 0.880 & & Close to \\
\hline & RMR & $<0.08$ & 0.038 & $\sqrt{ }$ & \\
\hline & RMSEA & $<0.08$ & 0.069 & $\sqrt{ }$ & \\
\hline \multirow{5}{*}{$\begin{array}{l}\text { Incremental } \\
\text { fitness }\end{array}$} & NFI & $>0.9$ & 0.912 & $\sqrt{ }$ & \\
\hline & NNFI(TLI) & $>0.9$ & 0.927 & $\sqrt{ }$ & \\
\hline & CFI & $>0.9$ & 0.938 & $\sqrt{ }$ & \\
\hline & RFI & $>0.9$ & 0.895 & & Close to \\
\hline & IFI & $>0.9$ & 0.939 & $\sqrt{ }$ & \\
\hline \multirow{2}{*}{$\begin{array}{l}\text { Simplified } \\
\text { fitness }\end{array}$} & PNFI & $>0.5$ & 0.769 & $\sqrt{ }$ & \\
\hline & PGFI & $>0.5$ & 0.686 & $\sqrt{ }$ & \\
\hline
\end{tabular}




\subsection{Analysis of test results}

Fitting results of hypothesis model and survey data of this study also demonstrate the three variables, GBA, GBSN and GBPC, significantly influence each other $(\mathrm{p}<0.001$, ***). Hypothesis 1 (H 1), hypothesis 2 (H2) and hypothesis $3(\mathrm{H} 3)$ are all supported. In addition, indicators of hypothesis 4 (H4) and hypothesis 6 (H6) also present significant influences $(\mathrm{p}<0.001, * * *)$ and these two hypotheses are supported. However, with respect to hypothesis 5 (H5), college students' GBSN has no significant influence on GBBI. As per Ajzen's (1991) theory of planned behavior, people's subjective norm of certain behaviors has direct and important influence on their behaviors. However, findings of the present study demonstrate college students' GBSN doesn't exert significant influence on their intention to participate in green building (as shown in table 5) (see figure 1).

Table 5. Interrelations between each variable.

\begin{tabular}{|c|c|c|c|c|c|c|}
\hline & & & Estimate & S.E. & C.R. & P \\
\hline \multirow{3}{*}{ GBBI } & $<---$ & GBPC & .573 & .063 & 9.154 & $* * *$ \\
\cline { 2 - 7 } & $<---$ & GBA & .216 & .047 & 4.571 & $* * *$ \\
\cline { 2 - 7 } & $<---$ & GBSN & -.017 & .027 & -.641 & .521 \\
\hline GBSN & $<-->$ & GBA & .164 & .029 & 5.688 & $* * *$ \\
\hline \multirow{2}{*}{ GBA } & $<-->$ & GBPC & .143 & .022 & 6.402 & $* * *$ \\
\hline GBSN & $<-->$ & GBPC & .224 & .034 & 6.656 & $* * *$ \\
\hline
\end{tabular}

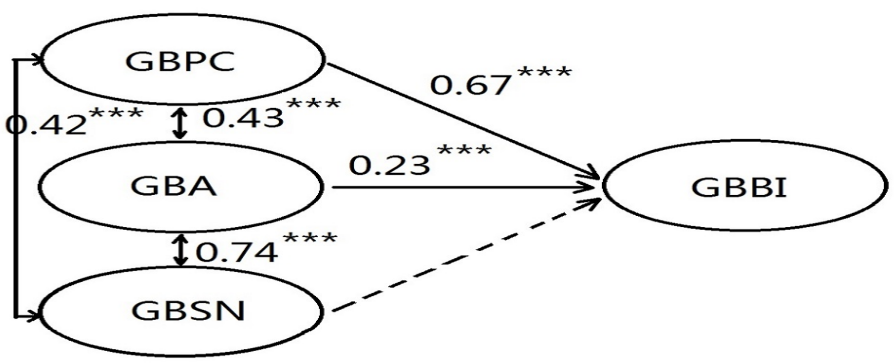

Figure 1. Structural equation of the intention to participate in green building.

\section{Conclusions}

Based on the theory of planned behavior proposed by Ajzen, this study investigates whether Fujian college students' "green building attitude", "green building subjective norm" and "green building perceived behavioral control" influence the intention to participate in the green building. A total of 443 valid questionnaires are obtained. Interviewees with different genders, family monthly incomes and majors show obvious differences in the intention to participate in green building. Analysis of structural equation model (SEM) shows GBA and GBPC have significant positive influence on GBBI but GBSN doesn't present such significant influence. The reason might be that college students are at the rebellious adolescence and unwilling to follow the direction of social norms, and have high self consciousness and own independent opinions. Therefore, GBSN cannot exert significant influence on the intention to participate in green building. L. Lin and X. Bai. (2014) ${ }^{[10]}$ made a research of university students' school work delay behavior and found these students' subjective norms don't 
have significant influence on behavioral intention. For analyzing consumers' intention to go shopping online, H. Zhang, C. Bai \& C. Li. (2011) ${ }^{[9]}$ investigated young and highly-educated netizen populations and found influence of subjective norm on online shopping intention was not significant. All these results support that young people's high self consciousness lead to insignificant influence of subjective norm on behavioral intention.

From results of this study we can see, students' more positive GBA and GBPC are associated with more positive intention to participate in the green building. Consequently, organizations such as governmental agencies and schools are suggested to promote green building in life and studying so that students will perceive close relationship between green building and current life. Furthermore, benefits brought by green building to the environment can also be emphasized so that students will realize practicing of green building can not only maintain environmental ecology but also enhance self image. Only in this way, students will have improvement in GBA, GBPC and GBBI.

The present study has some limitations. It doesn't conduct large-scale sampling. Objects of survey only include students of a university. There is no analysis of common people of the whole society. In the future, researchers should conduct survey among students of universities and colleges throughout the country so as to achieve more diverse and extensive samples and discussion space. In addition, more detailed influencing factors are not investigated. Future related researches are suggested to conduct further study of other factors.

\section{References}

1. Y. Wang, JCST, 7, 14-17 (2006)

2. W. Zhang and B. Li., JSTPP, 5, 16-17 (1998)

3. A. J. Hoffman and R. Henn, Org. \& Env., 21 (4), 390-419 (2008)

4. W. Zhang, Y. Huang, W. Xiao, L. Yang, and Z.J. Xiong, JHAS, 12, $75-77$ (2015)

5. X. Chen and Y. Li., J. Urb. and Arch., 33, 10-11 (2015)

6. X. Qin and L. Jing, CCEJ, 8, 123-135 (2013)

7. J. Zhang and Q. Zheng, JCE, 18 (1), 77-81 (2012)

8. K. Lao and J. Wu, JFS, 2, 91-100 (2013)

9. H. Zhang, C. Bai, and C. Li, JSS, 25 (9), 130-135 (2011)

10. L. Lin and X. Bai, CJCP, 22 (5), 855-859 (2014)

11. F. Boudreau and G. Godin, IJBNPA, 6 (1), 35-35 (2009)

12. I. Ajzen, OBHDP, 50 (2), 179-211 (1991) 